\title{
Chromosome 12q13.13q13.13 microduplication and microdeletion: a case report and literature review
}

\author{
Jie Hu ${ }^{1,2^{*}}$, Zhishuo Ou ${ }^{1}$, Elena Infante ${ }^{3}$, Sally J. Kochmar ${ }^{1}$, Suneeta Madan-Khetarpal ${ }^{3}$, Lori Hoffner ${ }^{4}$, \\ Shafagh Parsazad ${ }^{1}$ and Urvashi Surti, ${ }^{1,4}$
}

\begin{abstract}
Background: Duplications or deletions in the 12q13.13 region are rare. Only scattered cases with duplications and/ or deletions in this region have been reported in the literature or in online databases. Owing to the limited number of patients with genomic alteration within this region and lack of systematic analysis of these patients, the common clinical manifestation of these patients has remained elusive.

Case presentation: Here we report an $802 \mathrm{~kb}$ duplication in the 12q13.13q13.13 region in a 14 year-old male who presented with dysmorphic features, developmental delay (DD), mild intellectual disability (ID) and mild deformity of digits. Comparing the phenotype of our patient with those of reported patients, we find that patients with the 12q13. 13 duplication or the deletion share similar phenotypes, including dysmorphic facies, abnormal nails, intellectual disability, and deformity of digits or limbs. However, patients with the deletion appear to have more severe deformity of digits or limbs.

Conclusions: Deletion and duplication of the 12 q13.13 region may represent novel contiguous gene alteration syndromes. All seven reported 12q13.13 deletions and three of four duplications are de novo and vary in size. Therefore, these genomic alterations are not due to non-allelic homologous recombination.
\end{abstract}

Keywords: 12q13.13 Microdeletion/Microduplication, Array CGH, HOXC, SPT7, SP1

\section{Background}

There are only a handful of patients with a copy number variation $(\mathrm{CNV})$ in the $12 \mathrm{q} 13.13$ or $12 \mathrm{q} 13.13 \mathrm{q} 13.2$ region reported in the literature. Due to the variable sizes and number of genes involved in these CNVs, the common clinical features of these patients have not been identified. In the present study, we report one patient with a small 12q13.13q13.13 duplication and review genomic alterations and clinical features of additional four patients with a duplication and seven patients with a deletion, all of which are reported in the literature or in the DECIPHER (Database of genomic variation and phenotype in humans using ensembl resources) and dbVar (genomic structural

\footnotetext{
* Correspondence: jhu@upmc.edu

${ }^{1}$ Center for Clinical Genetics and Genomics, Pittsburgh Cytogenetics

Laboratory, Magee-Womens Hospital of UPMC, Pittsburgh, PA 15213, USA

${ }^{2}$ Department of Obstetrics, Gynecology \& Reproductive Sciences, University

of Pittsburgh School of Medicine, Pittsburgh, PA 15213, USA

Full list of author information is available at the end of the article
}

variation) databases. The common clinical features are detailed. The duplication and deletion of the 12q13.13q13.2 region may represent novel microdeletion and duplication syndromes.

\section{Case presentation}

Our patient is a 14 year 8-month-old male with dysmorphic features and a history of developmental delay, learning difficulties and disruptive behaviors. He was born at 35 weeks gestation to a 21-year-old gravida 1 , para 0 mother. The mother denied any use of medications. Fetal ultrasounds were normal. His birth weight was $2637 \mathrm{~g}$. He had mild jaundice at birth and remained in the hospital for 5 days due to breathing difficulties. He sat at 1 year of age, walked between 13 or 14 months of age, and did not speak any words until 3 and a half years of age. He had some regression of learning according to the family. At the age of 8 years he was evaluated 
by the Child Development Unit and diagnosed with Attention Deficit/Hyperactivity Disorder (ADHD). Genetic evaluation was performed on this patient at the age of 14 years and 8 months. At the time of the genetic evaluation, his weight was $47.2 \mathrm{~kg}$ (20th \%ile), height was $162 \mathrm{~cm}$ (22nd \%ile), and head circumference was $53.2 \mathrm{~cm}$ (30th \%ile). He had dolichocephaly with prominent occiput and a long and narrow face. His eyebrows were quite heavy with medial flare. His scalp hair was somewhat sparse and fine textured. He had telecanthus, with outer canthal distance (OCD) $9.6 \mathrm{~cm}$ (95th \%ile) and inner canthal distance (ICD) $3.9 \mathrm{~cm}$ (>97th \%ile). The cartilage of his ears was very soft and with Darwinian tubercle bilaterally. He had esotropia, narrow and short philtrum, bifid uvula, high palate, very broad nose in the middle as well as on the tip, and receding anterior hairline with widow's peak. His genitalia was barely at the beginning of Tanner II. He also had hyperconvexed nails, collapse of arches of his feet, slight scoliosis, and quite large-looking elbows with prominent carrying angles. His skin was dry with eczema on the dorsum and numerous moles, especially under his left eye. At the time of evaluation, he was in the eighth grade but was in special education classes working at a second grade level. The representative photos of this patient are shown in Fig. 1.

The mother of the patient is 36 years old with learning disabilities. As a child, she had developmental delay and had speech therapy, occupational therapy and physical therapy. She finished high school and is attending school to become "a nurse". The maternal grandmother also had developmental delays, special education, mental health concerns, and required speech therapy. The patient's father is in his 40's. He had delays and had learning disabilities. The patient's 7-year-old and 5-yearold maternal half-sisters had no concerns reported.

\section{Methods}

Microarray analysis was performed on purified DNA extracted from peripheral blood samples using Agilent's SurePrint G3 CGH + SNP microarray (4x180K ISCA design) platform. The array analysis followed the standard manufacturer protocols. Parental analysis was not performed because of unavailability of the samples.

\section{Results}

The whole genome CGH + SNP microarray analysis detected a gain in copy number in the $12 \mathrm{q} 13.13$ region (chr12:53,304,719-54,018,772, hg19) of the long arm of chromosome 12, encompassing at least $802 \mathrm{~kb}$ and containing 21 OMIM genes (KRT18, EIF4B, LOC283335, TENC1, SPRYD3, IGFBP6, SOAT2, CSAD, ZNF740, ITGB7, RARG, MFSD5, ESPL1, PFDN5, C12orf10, AAAS, SP7, SP1, AMHR2, PRR13, PCBP2, MAP3K12, TARBP, NPFF, ATF7). The array findings are shown in the top panel of Fig. 2.

\section{Discussion}

\section{Clinical features of patients with 12q13.13 duplication}

Our patient had an $802 \mathrm{~kb}$ interstitial duplication in the 12q13.13q13.13 region. He presented with mild ID, ADHD, language difficulty and dysmorphic features including dolichocephaly, prominent occiput, bifid uvula, high arched palate, long and narrow face, high arched heavy eyebrows with medial flare, hypertelorism, esotropia, broad nose bridge and tip, short philtrum, and receding anterior
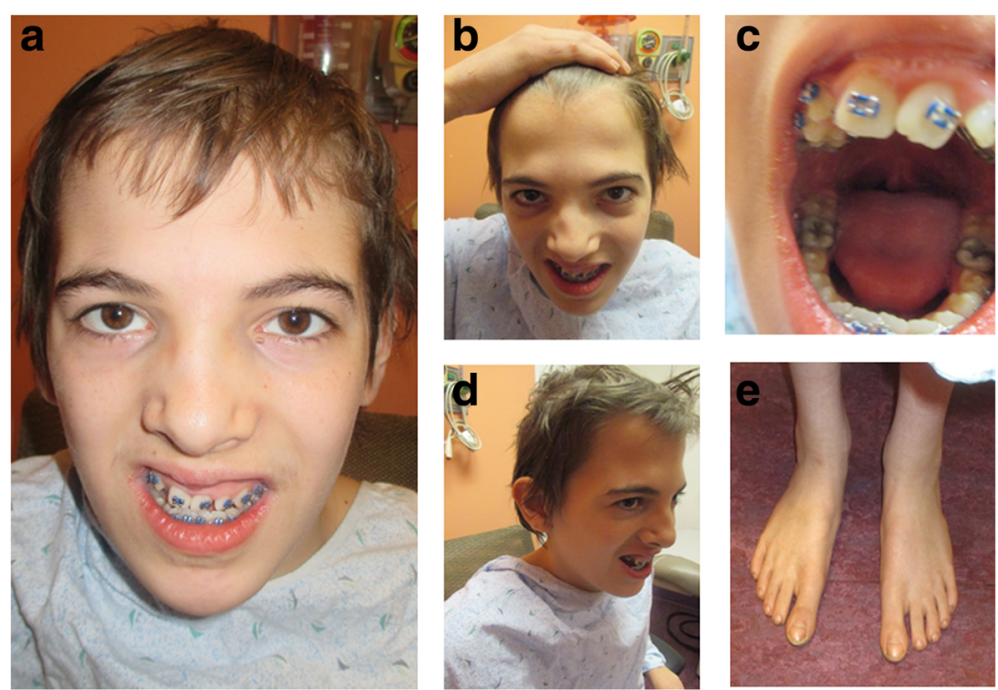

Fig. 1 Patient at age 14 years and 8 months of age. $\mathbf{a}$ and $\mathbf{b}$ : facial features of the patient including long and narrow face, high arched heavy eyebrows with medial flare, hypertelorism, moles under left eye, broad nasal bridge and tip, short philtrum; $\mathbf{c}$ : bifid uvula and abnormal tooth; $\mathbf{d}$ : a side view of the patient showing the low-set ear; e: abnormal toenails 


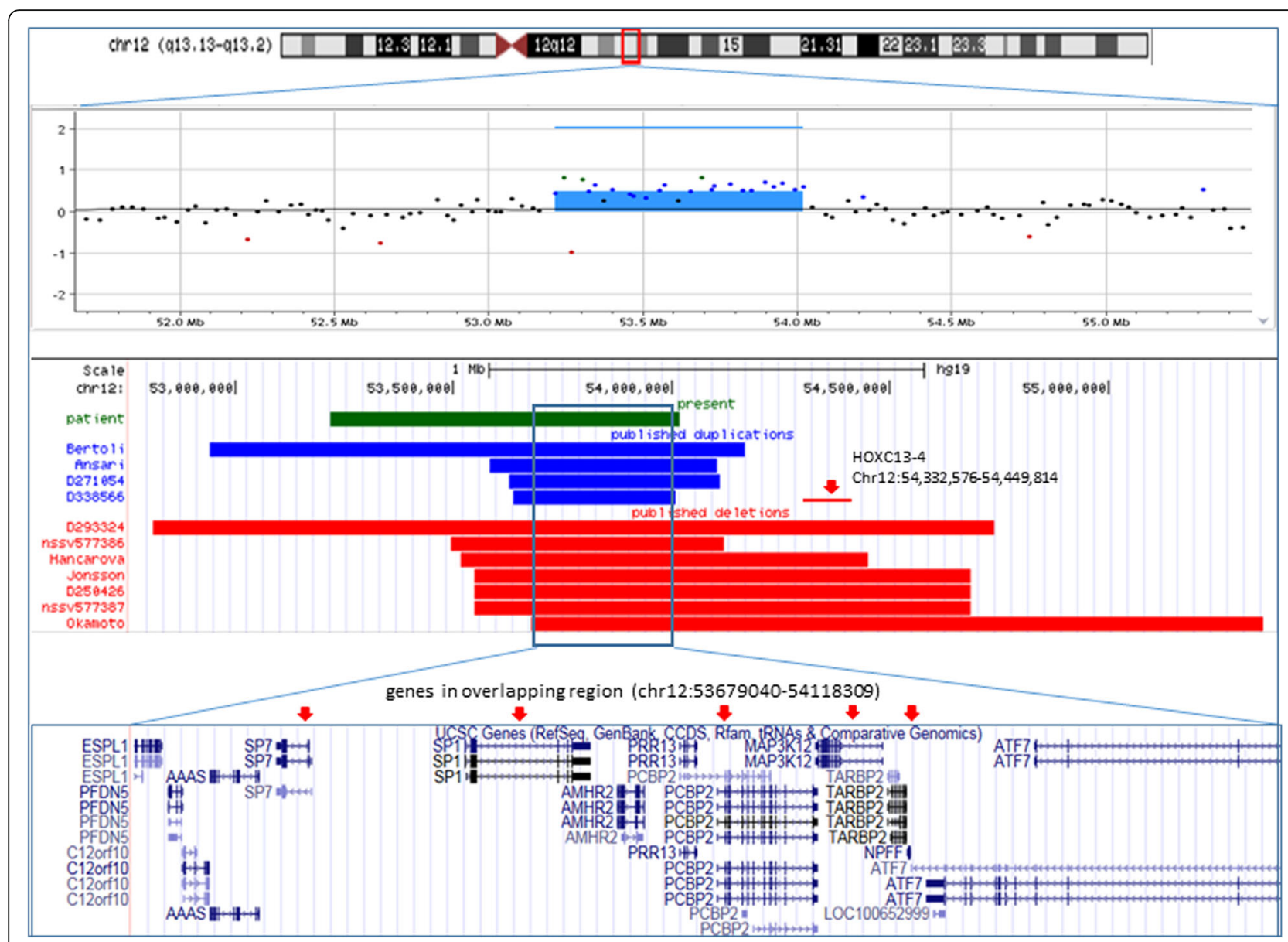

Fig. 2 Chromosome 12q13.13 or 12q13.13q13.2 duplications and deletions found in our patient and previously reported patients. The top panel shows the ideogram of chromosome 12 with the 12q13.13q13.2 region marked in a small red box. The scatter plot of the Agilent array-CGH data shows an $802 \mathrm{~kb}$ microduplication of 12q13.13 in our patient. The schematic representation in the middle panel shows a comparison of the duplications and deletions involving the 12q13.13 or 12q13.13q13.2 region in the 11 reported patients and our patient. The green bar represents the duplication detected in our patient; the blue bar bars represent duplications identified in previously reported patients; the red bars represent deletions identified in previously reported patients. The common region shared by the deletions and the duplications is shown in a box. The UCSC genes in the overlapping region are shown in the bottom panel. The red arrows point to the candidate genes

hairline. He also had coned-shaped epiphyses of distal phalanges of the 2nd-5th digits, hyperconvex nails, stubby thumbs and collapse of arches of both feet.

Four patients with a similar duplication in this region were reported in the literature $([1,2]$, DECIPHER 271054; DECIPHER 338566). The genome coordinates and size of the duplications, as well as phenotypes of all four reported patients and our patient are summarized in Table 1. The position of the duplications found in these patients are illustrated in the middle panel of Fig. 2. All five patients with duplication of the $12 \mathrm{q} 13.3$ region had ID, DD or language difficulties and dysmorphic facial features. The first patient, with a $1.2 \mathrm{Mb}$ duplication in the 12q13.13q13.2 region, was reported by Bertoli et al. [2]. The duplication interval in this patient completely covers the region of duplication in our patient. Our patient and the first reported patient share some facial features including craniofacial anomalies, trigonocephaly or dolichocephaly, cleft palate or high arched plate and bifid uvula, narrow face and heavy eyebrows. In addition, mild hand and foot anomalies were also seen in our patient and the first reported patient. Some similarities with Wolf-Hirschhorn syndrome were described in Bertoli's patient, such as high nasal bridge, shallow orbits, and hypertelorism, but these were not seen in our patient. It is noted that a patient with a larger duplication $(5 \mathrm{Mb})$ of this region was also reported to have Wolf-Hirschhorn syndrome-like phenotype [3]. Therefore, the variable phenotypes between our patient and the first reported patient are likely due to the size of the duplication and the genes that are involved. The second previously reported patient with a $520 \mathrm{~kb}$ duplication in the 12q13.13 region, was reported to have a Cornelia de Lange (CdLS)-like phenotype [1]. The third and the fourth patients reported in the 
Table 1 Laboratory findings and clinical features of 5 patients with 12q13.13 duplication

\begin{tabular}{|c|c|c|c|c|c|}
\hline Features & Present & Bertoli [2] & Ansari [1] & DECIPHER 271054 & $\begin{array}{l}\text { DECIPHER } \\
338566\end{array}$ \\
\hline Age/Gender & $14 / \mathrm{M}$ & $6 / F$ & NA/F & $14 / \mathrm{M}$ & $9 / F$ \\
\hline Size & $802 \mathrm{~Kb}$ & $1.2 \mathrm{Mb}$ & $520 \mathrm{~Kb}$ & $484 \mathrm{~Kb}$ & $370 \mathrm{~Kb}$ \\
\hline Chromosome regions & $12 q 13.13$ & $12 q 13.13 q 13.2$ & $12 q 13.13$ & $12 q 13.13$ & $12 q 13.13$ \\
\hline \multicolumn{6}{|l|}{ Genomic coordinates } \\
\hline$(h g 18)^{a}$ & & $51,227,241-52,353,011$ & & & \\
\hline (hg19) & $53,217,136-54,018,772$ & $52,940,974-54,166,744$ & $\begin{array}{l}53,582,733- \\
54,102,733\end{array}$ & $\begin{array}{l}53,627,092-54 \\
111,152\end{array}$ & $\begin{array}{l}53,637,649 \\
54,007,964\end{array}$ \\
\hline \# of genes & 27 & 57 & 18 & 16 & 17 \\
\hline HOXC cluster & None & None & None & None & None \\
\hline $\begin{array}{l}S P 1, S P 7, N P F F \\
M A P 3 K 12, P C B P\end{array}$ & Yes & Yes & Yes & Yes & Yes \\
\hline Inheritance & Unknown & De novo & Unknown & De novo & De novo \\
\hline Developmental Anomalies & ID, ADHD, language difficulty & ID, language difficulty & $D D, I D$ & ID & ID \\
\hline Craniofacial anomalies & $\begin{array}{l}\text { Dolichocephaly, prominent } \\
\text { occiput, bifid uvula, high } \\
\text { arched palate. }\end{array}$ & $\begin{array}{l}\text { Microcephaly, trigonocephaly } \\
\text { cleft palate }\end{array}$ & & & \\
\hline Dysmorphic facial features & $\begin{array}{l}\text { Long and narrow face, high } \\
\text { arched heavy eyebrows with } \\
\text { medial flare, hypertelorism, } \\
\text { esotropia, broad nasal } \\
\text { bridge and tip, short philtrum, } \\
\text { receding anterior hairlines, } \\
\text { auricular tubercle }\end{array}$ & $\begin{array}{l}\text { Long face, high arched } \\
\text { eyebrows, prominent glabella, } \\
\text { hypertelorism, prominent eye, } \\
\text { lagoph-thalmos, } \\
\text { shallow orbits, epicanthal folds, } \\
\text { hypoplastic nasal alae, high } \\
\text { nasal bridge, low-set ears, thin } \\
\text { upper lip }\end{array}$ & $\begin{array}{l}\text { CdLS-like } \\
\text { phenotype }\end{array}$ & $\begin{array}{l}\text { Abnormal face (no } \\
\text { details described) }\end{array}$ & \\
\hline Hand and foot anomalies & $\begin{array}{l}\text { hyperconvex nails, stub } \\
\text { thumbs, collapse of arches of } \\
\text { feet }\end{array}$ & $\begin{array}{l}\text { Small hands and feet, 2nd toe } \\
\text { clinodactyly }\end{array}$ & & & \\
\hline Skeletal anomalies & $\begin{array}{l}\text { Mild scoliosis, coned-shaped } \\
\text { epiphyses of distal phalanges } \\
\text { of } 2 \text { nd-5th digits }\end{array}$ & & & & \\
\hline Other & Dry skin, eczema on dorsum & $\begin{array}{l}\text { Ataxia walk, corneal sclerosis, } \\
\text { progeroid hands }\end{array}$ & & & \\
\hline
\end{tabular}

$A D H D$ attention deficit hyperactivity disorder, $C d L S$ Cornelia de Lange Syndrome, $D D$ developmental delay, ID intellectual disability;

${ }^{a}$ hg18 nucleotide coordinates in published patients are converted into hg19 nucleotide coordinates

DECIPHER database (patients: 271,054 and 338,566) were described to have intellectual disability. In addition, the patient (271054) also had abnormal facies. No other details of the clinical features were reported in those three patients. However, it is well known that the typical facial features for CdLS patients include arched eyebrows and synophrys, some with upper limb anomalies, and small, widely spaced teeth, which are similar features observed in patients with deletion/duplication of chromosome 12q13.13 [4].

It is interesting to note that deletions of this region were also reported in seven patients ([5-7], DECIPHER patients: 293,324 and 250,426; dbVar: nssv577386 and nssv577387). A comparison of the location and size of the deletions and duplications are illustrated in the middle panel of Fig. 2. The reported laboratory findings and clinical features of those patients with deletion of the 12q13.13 region are summarized in Table 2. It appears that patients with either a deletion or a duplication of this region share some common phenotypic abnormalities, including intellectual disability, similar facial dysmorphism (long face, high palate/cleft palate) and mild limb anomalies (clinodactyly of toes and stub thumbs). However, compared to the patients with a duplication of this region, patients with a deletion of this region had more severe limb deformities including camptodactyly or flexion contracture of hand, which were reported in five of the seven patients. Club foot or valgus position of the feet was reported in one patient each (DECIPHER patient: 293,324, [6]). Moreover, heart defects which were seen in some of patients with deletion of the 12q13.13 region were not observed in patients with duplication of the same region. Other skeletal abnormalities, such as scoliosis and coneshaped epiphyses of distal phalanges, reported in four of the seven patients with a 12q13.13 deletion ([5-7], 


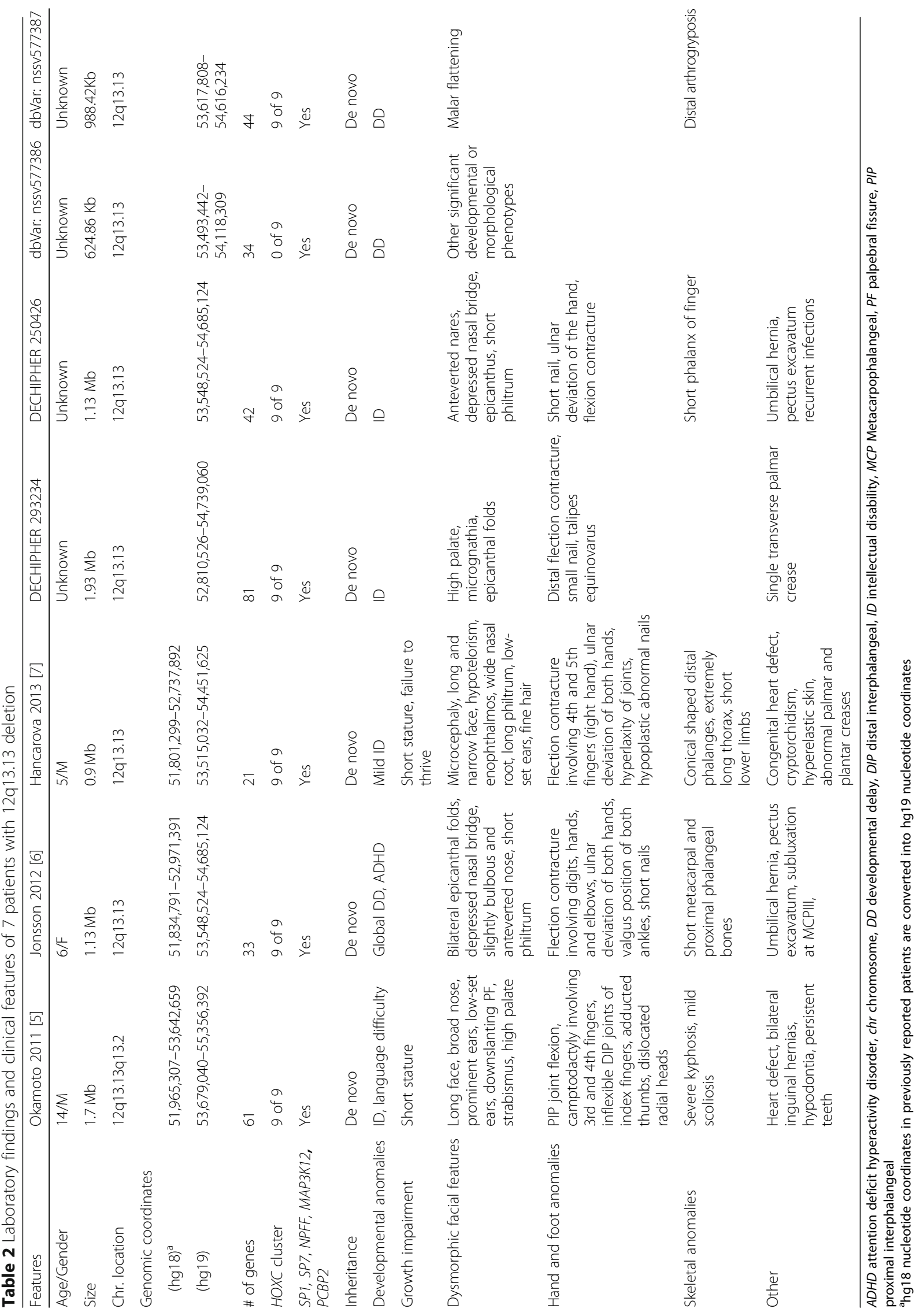


DECIPHER patient: 250,426), were also seen in our patient who had a duplication in this region.

\section{Candidate genes within the common deletion and duplication interval}

There are at least 16 genes within the common overlapping region. A few of these genes are expressed in the central nervous system and/or likely to be dosage sensitive, or reported to be associated with disease by animal studies. These genes could be candidate genes for patients with deletion or duplication in this region.

The transcription factor gene (SP1) is most likely to be dosage sensitive (haploinsufficiency score: 0.81\%) [DECIPHER]. The protein encoded by the $S P 1$ gene is a zinc finger transcription factor that binds to GC-rich motifs of many promoters and is then involved in a variety of cellular processes such as cell growth, apoptosis, differentiation and immune responses, DNA damage response, and chromatin remodeling (provided by RefSeq, Nov 2014). The SP7 gene (haploinsufficiency score: $14.4 \%$ ) encodes a bone specific transcription factor (osterix) which regulates osteogenesis and bone formation during embryonic development [8]. Niger et al. [9] reported that the activity of osterix $(\mathrm{Osx} / \mathrm{Sp} 7)$ is influenced by $\mathrm{Sp} 1$. The $s p 7^{-1-}$ mutation in zebra fish causes a generalized delay in osteoblast maturation, while heterozygous zebra fishes $\left(s p 7^{+1}-\right)$ are not appreciably different from wild type siblings, however; they exhibit an increase in the variance of craniofacial shape [10]. Dolichocephaly and trigonocephaly are seen in our patient and the first reported patient with a duplication in the 12q13.13 region. Moreover, 'long' or 'long and narrow' facies are a common feature in patients with a deletion or duplication in the 12q13.13 region. It is known that a homozygous single base pair deletion (c.1052delA) in the SP7 gene resulted in a child with osteogenesis imperfecta born to heterozygous carrier parents who were phenotypically normal [11]. However, the clinical features of the patients with heterozygous contiguous gene deletion/duplication involving both the SP1 and SP7 genes have not been investigated. Our study indicates that patients with either a deletion or a duplication of the $12 \mathrm{q} 13.13$ region, involving the $S P 1$ and $S P 7$ genes, share some common clinical features with those patients who have the homozygous SP7 mutation, such as short stature, high-arched palate, mild bone deformities, mild scoliosis, and delayed motor milestones. Whether concurrent dosage changes of the $S P 1$ and $S P 7$ genes cause some of the abnormal features in these patients is unclear at present.

The HOXC genes are not within the common duplication interval. However, six of seven reported patients with the 12q13.13 deletion involve the HOXC gene cluster, which are thought to be the candidate genes for the development of skeletal anomalies and limb deformities [5-7]. Mutations or deletions involving other $\mathrm{HOX}$ genes have been well documented in developmental disorders in both humans and mice, particularly limb anomalies [12]. Our earlier study found that patients with deletion of the $3^{\prime}$ portion (distal) of the HOXC

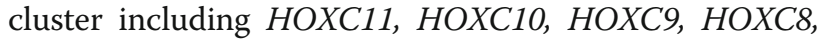
HOXC6, HOXC5 and HOXC4 showed no skeletal anomalies or obvious digit anomalies [13]. A recent study of multiple members from multiple generations in four families showed that the small deletions in the upstream noncoding region, with or without deletion of $\mathrm{HOXC13}$ and HOXC12, segregated with limb deformities [14], which indicates that a putative regulatory element within that region might be deleted in those patients. Variable expressivity including club foot, vertical talus, hammertoes and syndactyly was reported in those patients. Therefore, it is possible that a deletion of the 5 ' of $H O X C$ gene cluster may contribute to a relatively more severe phenotype in patients with the 12q13.13 deletion.

Developmental delay and intellectual disability were found in all patients with a 12q13.13 or 12q13.13q13.2 deletion/duplication. The common region for the copy number alterations in this region contains a few genes expressed in the central nervous system (NPFF, SP1, and $M A P 3 K 12)$. In addition to the $S p 1$ gene the heterogeneous nuclear riboprotein E2 ( $P C B P 2)$ gene is also predicted to be dosage sensitive with a haploinsufficiency score of 4.18\% [DECHIPHER]. Although the precise phenotype-genotype correlation for these genes cannot be established, the dosage changes of these genes may contribute to the neurodevelopmental anomalies in these patients. Although parental studies were unavailable for our patient, 10 of the 11 reported deletions or duplications were found to be de novo which supports the likely pathogenic nature of these CNVs.

\section{Conclusions}

We report one more patient with a chromosome 12q13.13 q13.13 duplication. The phenotype of this patient shows great similarity with the previously reported patients who have either a duplication or a deletion in this region, including a long face, high nasal bridge, high arched eyebrows, cleft palate, skeletal anomalies, limb deformity, language difficulty and intellectual disability. However, patients with deletion of this region have more severe skeletal anomalies, limb deformities and heart defects. Additional cases are needed to confirm these syndromes.

\section{Abbreviations}

aCGH: Array comparative genomic hybridization; ADHD: Attention deficit hyperactivity disorder; CdLS: Cornelia de Lange Syndrome; Chr: Chromosome; CNV: Copy number variation; DD: Developmental delay; DECIPHER: Database of genomic variation and phenotype in humans using ensembl resources; DIP: Distal interphalangeal; ICD: Inner canthal distance; ID: Intellectual disability; Kb: Kilobases; Mb: Megabases; MCP: Metacarpophalangeal; OCD: Outer canthal distance; OMIM: Online Mendelian Inheritance in Man; PF: Palpebral fissure; PIP: Proximal interphalangeal 


\section{Acknowledgements}

We acknowledge the patient and his family participating in this study. We also thank the staff at the Pittsburgh Cytogenetics Laboratory, Magee-Womens Hospital of UPMC for their technical support. All of the authors declared that they have no competing interests.

This study makes use of data generated by the DECIPHER community. A full list of centers who contributed to the generation of the data is available from http://decipher.sanger.ac.uk.

\section{Funding}

Not applicable.

\section{Availability of data and materials}

Data sharing not applicable to this article.

\section{Authors' contributions}

$\mathrm{JH}$ carried out the microarray analysis, medical chart review and data analysis. She also drafted and finalized the manuscript. El and SM collected the medical history and helped in the review of the patient's medical chart and participated in discussion of the clinical and laboratory findings. ZO and SP carried out the literature search and formatting of the manuscript and participated in discussion of the clinical and laboratory findings. SK, LH and US discussed the results and carried out the critical reading and editing of the manuscript. All the authors have read and approved the final manuscript.

\section{Competing interests}

The authors declare that they have no competing interests.

\section{Consent for publication}

Informed written consent for publication of the clinical details was obtained from the patient's family. A copy of the consent form is available for inspection by the editors.

\section{Ethics approval and consent to participate}

This study involves a single case medical chart review. Parents of the patient have given their informed written consent for participation in this study.

\section{Publisher's Note}

Springer Nature remains neutral with regard to jurisdictional claims in published maps and institutional affiliations.

\section{Author details}

${ }^{1}$ Center for Clinical Genetics and Genomics, Pittsburgh Cytogenetics Laboratory, Magee-Womens Hospital of UPMC, Pittsburgh, PA 15213, USA. ${ }^{2}$ Department of Obstetrics, Gynecology \& Reproductive Sciences, University of Pittsburgh School of Medicine, Pittsburgh, PA 15213, USA. ${ }^{3}$ Department of Genetics, Children's Hospital of Pittsburgh of UPMC, Pittsburgh, PA 15224, USA. ${ }^{4}$ Department of Pathology, University of Pittsburgh School of Medicine, Pittsburgh, PA 15213, USA

Received: 1 March 2017 Accepted: 8 June 2017

Published online: 19 June 2017

\section{References}

1. Ansari M, Poke G, Ferry Q, Williamson K, Aldridge R, Meynert AM, et al. Genetic heterogeneity in Cornelia de Lange syndrome (CdLS) and CdLS-like phenotypes withobserved and predicted levels of mosaicism. J Med Genet. 2014:51:659-68.

2. Bertoli M, Alesi V, Gullotta F, Zampatti S, Abate MR, Palmieri C, et al. Another patient with 12q13 microduplication. Am J Med Genet A. 2013;161A:2004-8.

3. Dallapiccola B, Bernardini L, Novelli A, Mingarelli R. Phenocopy of WolfHirschhorn syndrome in a patient with duplication 12q13.3q14.1. Am J Med Genet A. 2009;149A:546-8.

4. Deardorff MA, Noon SE, Krantz ID, editors. Cornelia de Lange Syndrome. Seattle: University Of Washington; 2005. p. 1993-2016.

5. Okamoto N, Tamura D, Nishimura G, Shimojima K, Yamamoto T. Submicroscopic deletion of 12q13 including HOXC gene cluster with skeletal anomalies and global developmental delay. Am J Med Genet A. 2011;155A:2997-3001.

6. Jonsson DI, Ludvigsson P, Aradhya S, Sigurdardottir S, Steinarsdottir M Hauksdottir H. A de novo $1.13 \mathrm{Mb}$ microdeletion in 12 q13.13 associated with congenital distal arthrogryposis, intellectual disability and mild dysmorphism. Eur J Med Genet. 2012;55:437-40.

7. Hancarova M, Simandlova M, Drabova J, Petrak B, Koudova M, Havlovicova $\mathrm{M}$, et al. Chromosome 12q13.13 deletions involving the HOXC gene cluster: phenotype and candidate genes. Eur J Med Genet. 2013;56:171-3.

8. Nakashima K, Zhou X, Kunkel G, Zhang Z, Deng JM, Behringer RR. The novel zinc finger-containing transcription factor osterix is required for osteoblast differentiation and bone formation. Cell. 2002;108:17-29.

9. Niger C, Lima F, Yoo DJ, Gupta RR, Buo AM, Hebert C, et al. The transcriptional activity of osterix requires the recruitment of Sp1 to the osteocalcin proximal promoter. Bone. 2011:49:683-92.

10. Kague E, Roy P, Asselin G, Hu G, Simonet J, Stanley A. Osterix/Sp7 limits cranial bone initiation sites and is required for formation of sutures. Dev Biol. 2016:413:160-72.

11. Lapunzina P, Aglan M, Temtamy S, Caparros-Martin JA, Valencia M, Leton R. Identification of a frameshift mutation in osterix in a patient with recessive osteogenesis imperfecta. Am J Hum Genet. 2010;87:110-4.

12. Goodman FR. Limb malformation and the human HOX genes. Am J Med Genet. 2002:112:256-65.

13. Peterson JF, Hartman J, Ghaloul-Gonzalez L, Surti U, Hu J. Absence of skeletal anomalies in siblings with a maternally inherited 12q13.13-q13.2 microdeletion partially involving the HOXC gene cluster. Am J Med Genet A. 2014;164A:810-4.

14. Alvarado DM, McCall K, Hecht JT, Dobbs MB, Gurnett CA. Deletions of 5' HOXC genes are associated with lower extremity malformations, including clubfoot and vertical talus. J Med Genet. 2016:4:1-6.

\section{Submit your next manuscript to BioMed Central and we will help you at every step:}

- We accept pre-submission inquiries

- Our selector tool helps you to find the most relevant journal

- We provide round the clock customer support

- Convenient online submission

- Thorough peer review

- Inclusion in PubMed and all major indexing services

- Maximum visibility for your research

Submit your manuscript at www.biomedcentral.com/submit
) Biomed Central 